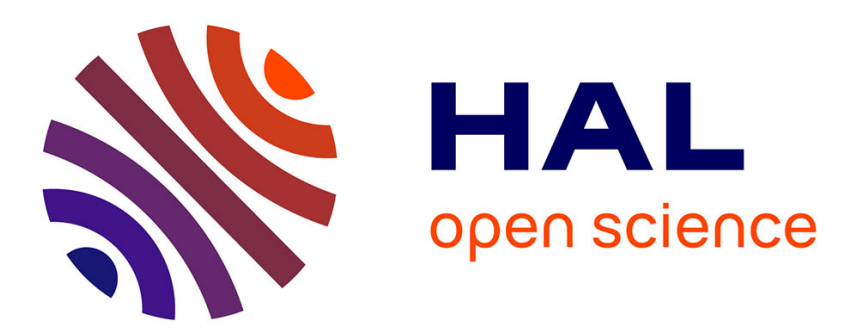

\title{
Real-Time Inundation Mapping with a 2D Hydraulic Modelling Tool Based on Adaptive Grid Refinement: The Case of the October 2015 French Riviera Flood
}

Geoffroy Kirstetter, François Bourgin, Pierre Brigode, Olivier Delestre

\section{- To cite this version:}

Geoffroy Kirstetter, François Bourgin, Pierre Brigode, Olivier Delestre. Real-Time Inundation Mapping with a 2D Hydraulic Modelling Tool Based on Adaptive Grid Refinement: The Case of the October 2015 French Riviera Flood. Advances in Hydroinformatics, 2020, Springer Water, 10.1007/978981-15-5436-0_25. hal-02955433

\section{HAL Id: hal-02955433 \\ https://hal.science/hal-02955433}

Submitted on 5 Oct 2020

HAL is a multi-disciplinary open access archive for the deposit and dissemination of scientific research documents, whether they are published or not. The documents may come from teaching and research institutions in France or abroad, or from public or private research centers.
L'archive ouverte pluridisciplinaire HAL, est destinée au dépôt et à la diffusion de documents scientifiques de niveau recherche, publiés ou non, émanant des établissements d'enseignement et de recherche français ou étrangers, des laboratoires publics ou privés. 


\title{
Real-Time Inundation Mapping with a 2D Hydraulic Modelling Tool Based on Adaptive Grid Refinement: The Case of the October 2015 French Riviera Flood
}

\author{
G. Kirstetter; F. Bourgin† P. Brigode ${ }^{\ddagger}$ O. Delestre ${ }^{\S}$
}

October 5, 2020

\begin{abstract}
The vulnerability of the French Riviera territories to hydro-meteorological hazards has been highlighted by the flash flood of the 3rd of October 2015, which had catastrophic consequences. In the view of the speed and violence of these phenomena, the development of warning systems able to provide real-time flood mapping should make it possible to limit their impacts. In this context, the main objective of this work is to study the feasibility of using a 2D hydraulic modelling tool with adaptive grid refinement, the Basilisk calculation code http://basilisk.fr/, which is based on state-of-the-art finite volume methods. This code has been used to model the October 2015 flood event on one French Riviera coastal catchment, the Brague River catchment. Results obtained with Basilisk were compared with available information from post-event surveys, showing promising performances in terms of simulated peak discharges, inundation extent and water levels in the floodplain. These results highlight that forecasting inundation extents generated by flash flood events on small watersheds (less than $100 \mathrm{~km}^{2}$ ) is possible at a moderate computational cost.
\end{abstract}

\section{Introduction}

Mostly in autumn, watersheds of French Riviera are frequently subject to flash floods due to short duration and high intensity rainfall events. This occurs on small and medium watersheds (generally less than $100 \mathrm{~km}^{2}$ ) with steep slopes which leads to short hydrological responses, from a few minutes to a few hours. Most of the downstream parts of these watersheds are urbanized. These extreme events represent a real threat on human life and on property (private damages, activities, cars, etc.). It is thus necessary to accurately forecast the dynamic of the flood event and its associated inundation map in order to help authorities to anticipate and take appropriate decisions in a real-time crisis situation.

It becomes necessary to model that type of event accurately in the description of the dynamic and of the extent of the flood. Previous works have been done in one and two dimensional hydraulic modelling. A catalogue of flood maps can be generated offline and then can be used in real-time from flow forecasting, for example using the simplified 1D hydraulic modelling setup approach presented by Le Bihan et al. [7], 1D/2D coupling [5] or other 2D hydraulic model approaches such as steady state modelling [4] and synthetic flood events generation. A recent review of several approaches can be found in Teng et al. [14].

On one hand, the main limitations of 1D approaches are accuracy and inability to provide a good description of the floodplain, while it provides computational efficiency that allows real-time simulations. On the other hand, high-resolution 2D approaches can provide a better representation of the flood dynamics in complex settings, but they are still very expensive in terms of computational costs and require user expertise (e.g. [3], [9]).

This work aims at exploring an alternative approach, which consists in using a 2D hydraulic modelling tool based on adaptive grid refinement and shallow-water equations to provide real-time inundation mapping applied to a watershed having a short hydrological response. The main challenge lies in obtaining a dynamical description of the inundation in a forecasting context, i.e., the computational time has to stay very limited compared to the real life duration of the event.

We propose to test our approach on a typical coastal watershed of the French Riviera, the Brague River catchment $\left(68 \mathrm{~km}^{2}\right)$, on the flash flood that occurred during the rainfall event of the 3rd of October 2015. During this event, 650 billion of insured damage and 20 casualties were reported (source: http://basilisk.fr/, see also [10]. As a first step, we describe the watershed of the Brague River and the rainfall event of the 3rd of October 2015. Then we present the open source software Basilisk, the obtained results and future work perspectives.

\footnotetext{
*Université Côte d'Azur, CNRS, LJAD, Polytech Nice Sophia, France, e-mail: geoffroy.kirstetter@univ-cotedazur.fr

${ }^{\dagger}$ IFSTTAR, GERS, EE, Bouguenais, France, e-mail: francois.bourgin@ifsttar.fr

¥Université Côte d'Azur, Observatoire de la Côte d'Azur, CNRS, IRD, Géoazur, France, e-mail: pierre.brigode@univ-cotedazur.fr

§Université Côte d'Azur, CNRS, LJAD, Polytech Nice Sophia, France, e-mail: olivier.delestre@univ-cotedazur.fr
} 


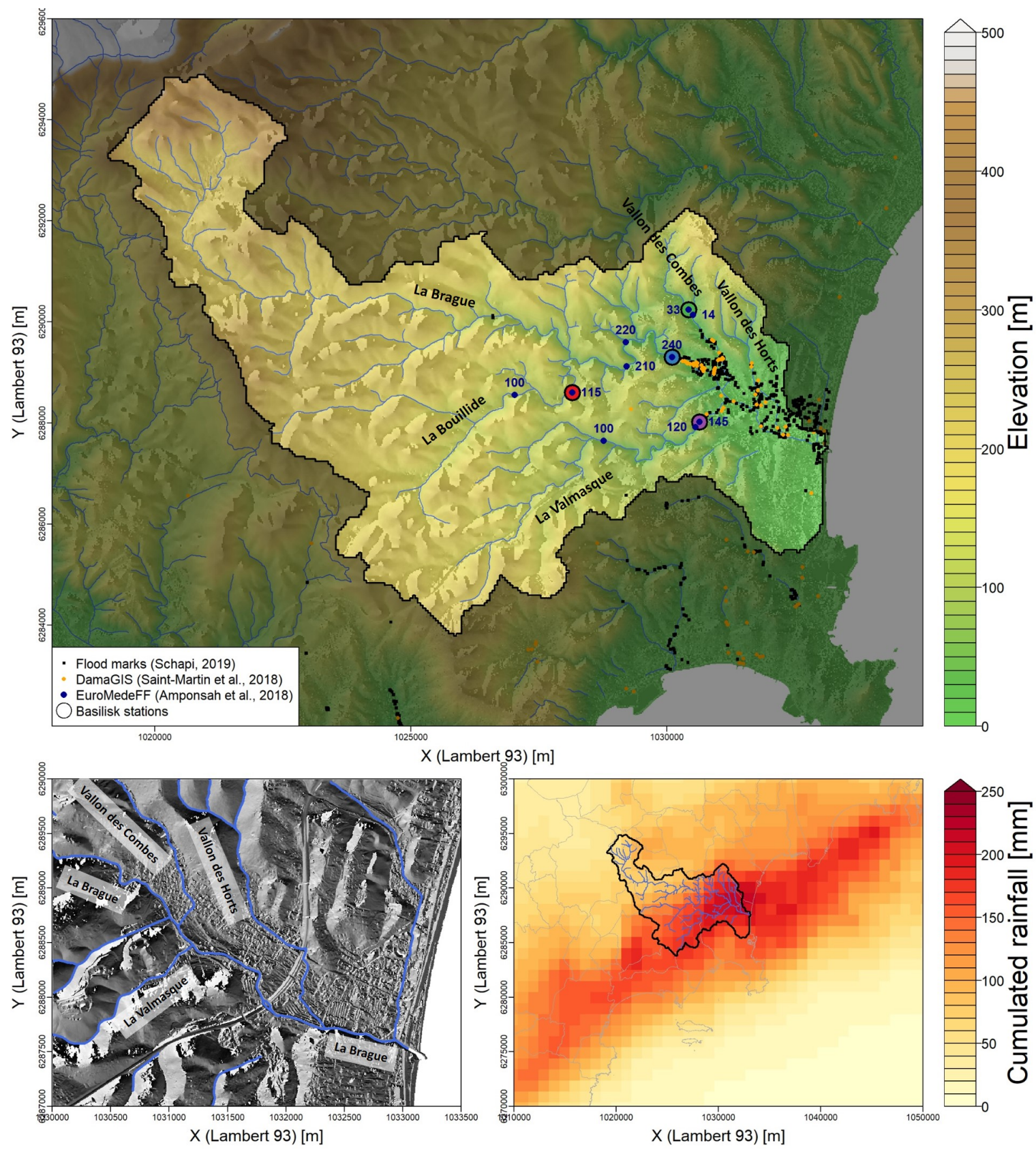

Figure 1: (top) Elevations of the Brague watershed, position of flood marks (Schapi [13]), and observed damages [12]. Blue points show the sections where maximum flood flows have been estimated by Amponsah et al. [1], and the estimated peak discharge values are indicated (in $\mathrm{m}^{3} / \mathrm{s}$ ). Note that temporal series of river discharges have been estimated at four of these particular sections, noted as Basilisk stations (colored points). (bottom left) Zoom on the elevations at the Brague watershed outlet, where simulated inundation extents will be highlighted. (bottom right) Cumulated PANTHERE rainfall during the 3rd October 2015. 


\section{Materials and methods}

\subsection{The Brague River Watershed}

The Brague River watershed is located in the French Riviera, near Antibes, Alpes-Maritimes (Fig. 1). It is a costal Mediterranean catchment of $68 \mathrm{~km}^{2}$ prone to regular flash floods, with marked elevations in the upper hills of the basin and an urbanised lower part in the floodplain near the coast.

\subsection{Datasets Used}

\subsubsection{Digital Elevation Model}

We used the Digital Elevation Model (DEM) RGE ALTI at $1 \mathrm{~m}$ resolution provided by IGN (http://professionnels . ign.fr/rgealti). The DEM was aggregated at $4 \mathrm{~m}$ resolution for the hydraulic model.

\subsubsection{Rainfall}

We used the rainfall data from the PANTHERE product of Météo-France for the 3rd October. The PANTHERE product is derived from radar data, it has a spatial resolution of $1 \mathrm{~km}^{2}$ and a rainfall grid is provided every 5 min. The cumulated rainfall for the 3rd October in the Brague area is illustrated in Fig. 1.

\subsubsection{Peak Discharge Estimations and Flood Marks}

Several post-event investigations were launched to understand and document the 2015 catastrophic event. In particular, a post-event study carried out within the HyMeX program results in peak discharge estimations at several locations along the main streams that flow into the Brague floodplain, as illustrated in Fig. 1. The database is open-access and described in Amponsah et al. [1]. In addition, we used several flood marks available through the open-access national platform (https://www.reperesdecrues.developpement-durable.gouv. fr, Schapi [13]) and other observed damages documented in Saint-Martin et al. [12].

\subsection{Basilisk Software}

\subsubsection{Leading Equations}

We used the open-source software Basilisk (http://basilisk.fr/) to model the system. Because overland flows are well-described by the Saint-Venant equations, also known as the shallow-water equations, we used this system to mimic the physics of the hydraulics process. The rigorous derivation of the Saint-Venant equations with rain can be found in Zhang and Cundy [16]. The rain intensity is added as a source term in the mass conservation equation. The Manning friction term is added as source term in the momentum conservation equation.

\subsubsection{Numerical Scheme}

The shallow-water equations are discretized by the finite volume method. The time is discretized with time-step $\Delta t>0$ and the space is discretized with square cell of different size, as explained in the next section. We name $\Delta$ the length of ridge of square cells. We use the second-order hydrostatic reconstruction scheme introduced by Audusse et al. [2]. This scheme conserves lake-at-rest state and preserve positivity of water depth. The numerical flux is solved by the Godunov-like approximate Riemann solver developed by Kurganov and Levy [6]. We use a predictor-corrector scheme to increment the time and we use a simple time-splitted method to deal with the source terms like friction and rain.

\subsubsection{Quadtree-Adaptive Grid Refinement}

Many schemes solve the Saint-Venant or the Boussinesq equations on a regular Cartesian grid. This method ensures a maximal precision but at a cost of computational time, which typically scales like $\Delta^{3}$. With this kind of method, to divide by a factor 2 the spatial resolution, we have to multiply by 8 the computational time. Here, we use the quadtree adaptive refinement approach proposed by Popinet [11] to drastically decrease this factor and limit the computational burden. Basilisk provides a strategy for refinement and coarsening that is applied at each time steps by comparing a chosen scalar field obtained at different spatial resolutions. Refinement occurs when the difference between the value of the scalar field obtained as the average of the four child cells and the value of the parent cell is greater than a threshold value. Conversely, coarsening occurs when the same difference is smaller than the threshold. Thus, the threshold value can be seen as the allowable error between two levels of refinement. 

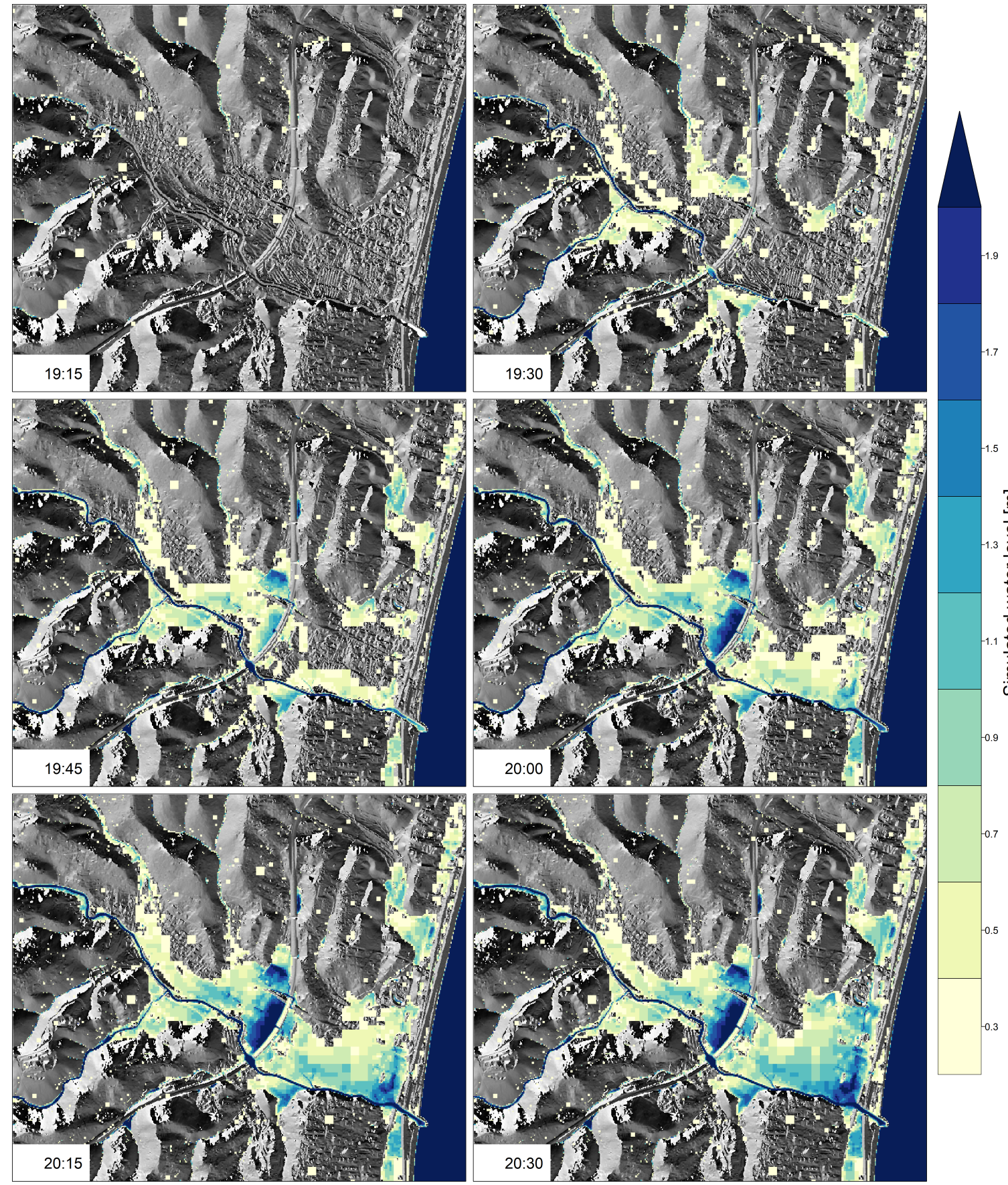

Figure 2: Simulated flood extents obtained with the reference simulation, from 19:15 to 20:30 TU: only the pixels with more than $20 \mathrm{~cm}$ of water are highlighted here. 


\subsection{Soil Conservation Service - Curve Number (SCS-CN)}

To account for interception, rainfall-excess time series are estimated fromthe rainfall time series with the wellknown and widely used SCS-CN approach (USDA, [15]). For each pixel of the rainfall field, the SCS loss model is applied with a $\mathrm{CN}$ value of 70 . We did not account for spatial variability of the $\mathrm{CN}$ values in the Brague catchment since the analysis carried out during the post-event study [8] suggested that a constant $\mathrm{CN}$ value of 70 was adequate for the flood event of the 3rd of October.

\subsection{Simulation Setup}

We used the following simulation setup:

- a uniform value of 0.05 for the Manning coefficient,

- the water height as the scalar field used for refinement and coarsening with an error threshold equal to $20 \mathrm{~cm}$,

- grid cell resolutions ranging from $4 \mathrm{~m}$ for the highest resolution and $66 \mathrm{~m}$ for the lowest resolution.

To assess the computational efficiency and the feasibility of real-time inundation mapping based on real-time precipitation forecasts, we performed three different simulations on a Linux virtual machine with 16 Intel(R) Xeon(R) CPU E5-2650-v4 2.20 GHz processors, by limiting the highest grid cell resolution at 16,8 and $4 \mathrm{~m}$ respectively. These three simulations will be named LR (low resolution), MR (medium resolution) and HR (high resolution) hereafter. Computational times of 15, 60 and 238 min were obtained when simulating the three-hour event of the 3rd October, from 18:30 to 21:30 TU. The number of cells at the end of each simulation is respectively 98845,149407 and 224500, which explains the difference in computing time.
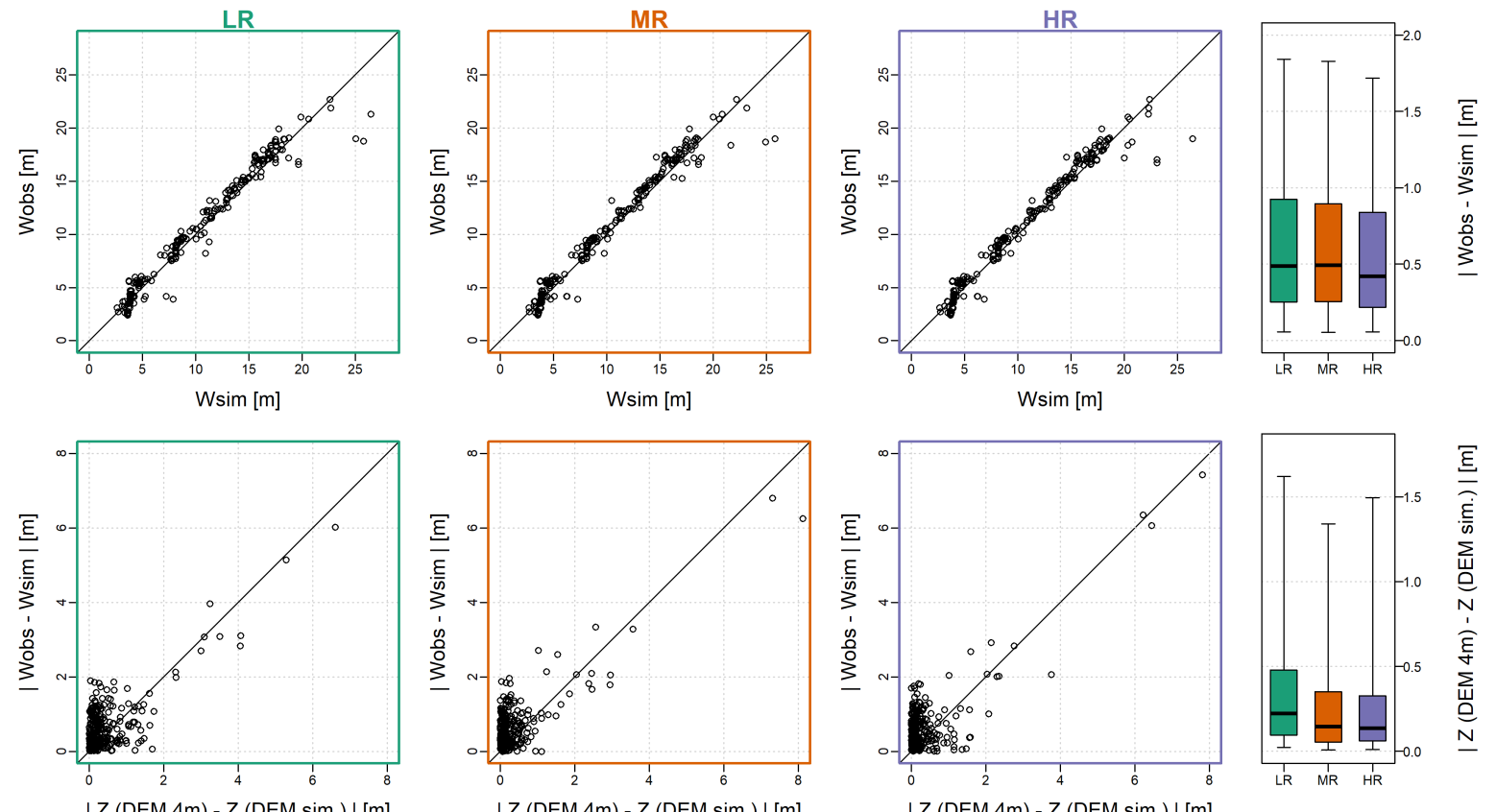

Figure 3: (top) Scatter plot between observed and simulated water elevation values for the three different simulations. The boxplots $(5,25,50,75$ and 95 th quantiles) summarizes the distributions of absolute differences. (down) Scatter plot between absolute differences water elevation errors and the differences between elevation values due to the variable grid resolution for the three different simulations.

\section{Results}

\subsection{Inundation Extent}

\subsubsection{Temporal Dynamic of the Reference Simulation MR}

Figure 2 shows the temporal dynamic of the simulated flood by showing flooded areas (pixels with more than $20 \mathrm{~cm}$ of water) at six different time steps, starting at 19:15 TU. At this timestep, water is coming within the 
different valleys (e.g. Vallon des Combes). At 19:30, we see the first flooded areas, such as the Valmasque outlet (right bank of the Brague river), the Vallon des Horts outlet (left bank) and downstream of the A6 highway (right bank). 15 min later, the place called la Plaine de Biot, at the junction of the Vallon des Combes and the Brague river is flooded, as the junction of the Valsmasque and the Brague river and the entire left bank flood plain, upstream from the A6 highway. At 20:00, the entire Brague flood plain is flooded, both upstream and downstream from the A6 highway. For the next $30 \mathrm{~min}$, the inundation extent seems to be constant.
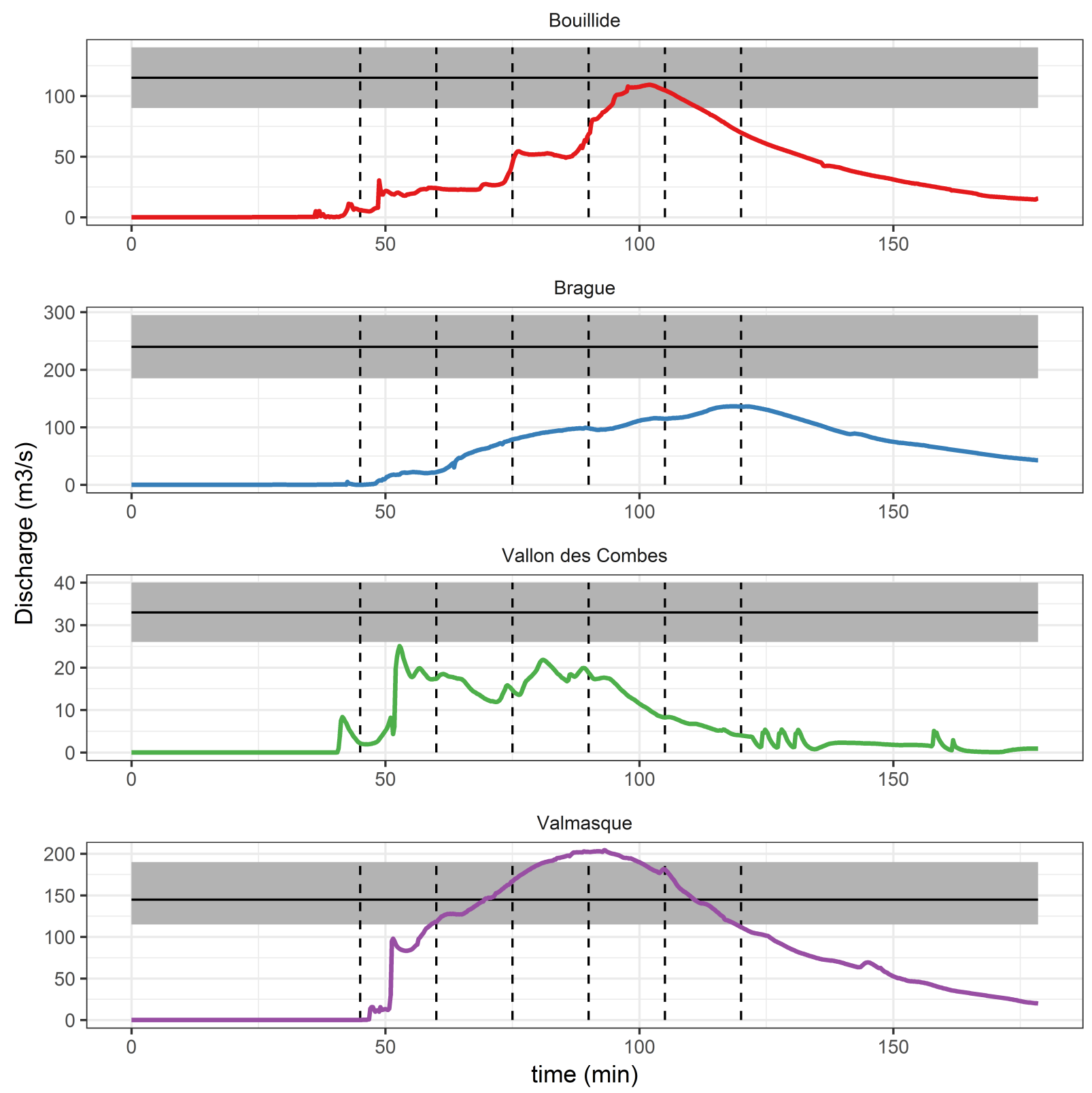

Figure 4: Hydrographs estimated from the reference simulation at four locations (see Fig. 1). The estimated values and their uncertainty from the post-event survey reported in Amponsah et al. [1] are shown as a gray range and a black line as no timing information was available. Starting time is 18:30 TU. Vertical dashed lines showed the six time steps for which the inundation extent is illustrated in Fig. 2.

\subsubsection{Impact of the Spatial Resolution on Simulated Flood Extent and Performances}

The difference of flood simulation extents obtained with the three simulations is limited (not shown). For the three simulations, more than $89 \%$ of the available 391 flood marks are located within the simulated inundation extents $(89.5 \%, 91.8 \%$ and $93.4 \%$ for the low, reference and high resolution simulations, respectively).

Figure 3 (top) shows the general performances obtained by the three different simulations in terms of simulation of water elevation values obtained at 276 points (out the 391 flood marks) where flood marks and water 
elevation values are available [13]. The highest resolution simulation (HR) produces better results than the lowest resolution simulation (LR), and the reference simulation (MR) stands in between, with median absolute difference values of $0.49,0.49$ and $0.42 \mathrm{~m}$ for $\mathrm{LR}, \mathrm{MR}$ and $\mathrm{HR}$ respectively.

It is interesting to note that the largest errors could be explained by significant differences between elevations of the reference DEM ( $4 \mathrm{~m}$ resolution) and elevations used during the simulation (up to $66 \mathrm{~m}$ for the lowest resolution), as shown in Fig. 3 (bottom), where the water elevation errors for each of the 276 points is plotted against the elevation differences. This can be explained by our choice of the refinement criteria that only takes into account the water height and not the water elevation and thus does not necessarily lead to refining areas with steep elevation gradients.

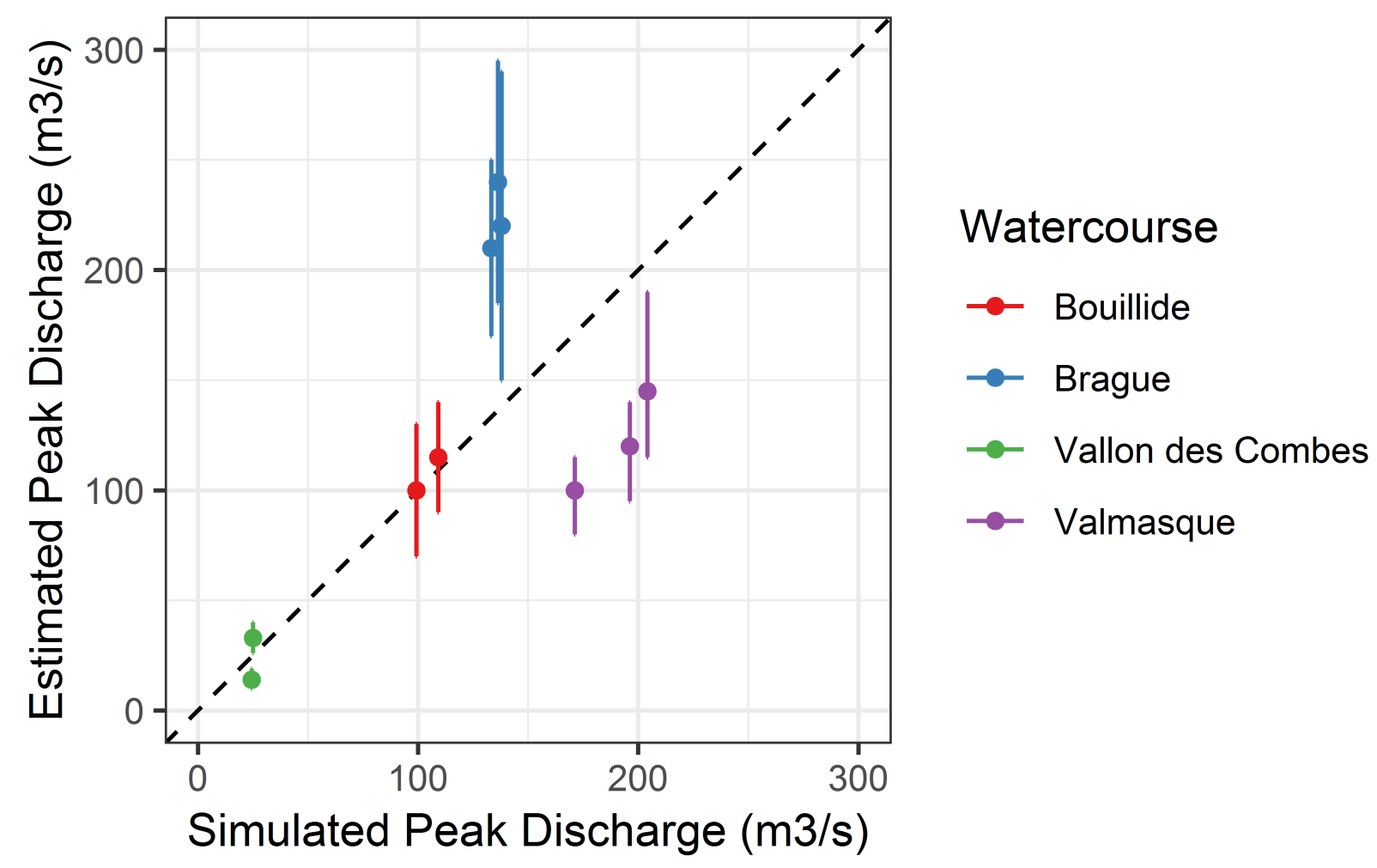

Figure 5: Comparison between simulated peak discharge values and minimum and maximum estimated peak discharge values from the post-event survey reported in Amponsah et al. [1] at ten locations along the four main watercourses.

\subsection{Simulated Hydrographs}

Figure 4 shows the hydrographs estimated from the reference simulation for the main four watercourses that are located upstream the Brague floodplain, as illustrated in Fig. 1. Discharge values were estimated by extracting the velocity and the height of water across the grid cells belonging to vertical or horizontal cross sections, depending of the shape of the river valley. The flood event was sudden and the simulated hydrographs suggest a fast hydrological response with time to peak duration ranging froma few minutes for the Vallon des Combes to one hour for the Brague River. The maximum discharge values obtained from the reference simulation seem to be within the range of estimated values from the post-event survey, although an underestimation can be seen for the Brague River and a slight overestimation for the Valmasque River.

Furthermore, we compared the simulated peak discharge values to the estimated peak discharge values from the post-event survey at ten locations shown in Fig. 1. Figure 5 confirms that the simulated discharge values along the Brague River are underestimated, while the discharge values at the locations along the Valmasque stream appear to be slightly overestimated. The peak discharge values for the Bouillide stream and the Vallon des Combes stream are in a good agreement with the values from the post-event survey. 
Overall, those results suggest that the simple approach of SCS-CN used to estimate the net rainfall is sufficient to yield acceptable peak discharge estimations for this event. Nonetheless, it should be remembered that the constant $\mathrm{CN}$ value of 70 we used was based on a preliminary work carried out during the post-event study on this event.

\section{Conclusions}

In the French Riviera, most of the urban zones are concentrated near the coast due to the mountainous relief. Upstream areas of these urban zones are small or medium size catchment with steep slopes. Thus, the short response time of those watersheds combined to the high intensity and the short duration of autumnal rainfall event frequently result in devastating flash floods. These catastrophic extreme events are a threat to the population life and to properties and it becomes clearly necessary to have forecasting tools with a good description of the dynamic of the event.

We investigated the feasibility of using a physically-based approach in order to tackle this issue. Because a standard approach was not appropriate due to too high computational times, we used a $2 \mathrm{D}$ approach based on adaptive mesh refinements. In this context, there is a trade-off between the levels of grid refinement, the accuracy of the results and the computational time costs. The results obtained on the Brague River watershed $\left(68 \mathrm{~km}^{2}\right)$ show that this alternative is a promising solution to the problem raised: getting a forecast of flash flood events on watersheds of less than $100 \mathrm{~km}^{2}$ with reasonable computational cost is possible, with good performances in terms of maximum discharges, inundation extent and water levels.

Some improvements could be obtained by a treatment of the DEM to correct some elevation artefacts, and by finding another refinement criteria of the mesh adaptation, both in time and space. In addition, this study has some limitations regarding the choice of the production function (SCS-CN) and the Manning coefficient and further work is needed to investigate the impact of these hypotheses in a real-time forecasting situation.

Moreover, a strategy of coupling rainfall-runoff modelling on the upper parts of the studied watershed and hydraulic modeling on the lower parts (with high stakes) might be tested to further reduce the computational costs. In future works, this general approach will be applied on the same catchment with other rainfall events and on other catchments to confirm the genericity of the approach. Complementary, the adaptive grid refinement approach will be compared with results obtained with other state-of-the art inundation modeling approaches.

\section{Acknowledgments}

The authors thank Météo-France for providing the meteorological data and IGN for the elevation data. This work is supported by the EU-funded project Risq'Eau (Interreg ALCOTRA project).

\section{References}

[1] W. Amponsah, P.-A. Ayral, B. Boudevillain, C. Bouvier, I. Braud, P. Brunet, G. Delrieu, J.-F. DidonLescot, E. Gaume, L. Lebouc, L. Marchi, F. Marra, E. Morin, G. Nord, O. Payrastre, D. Zoccatelli, and M. Borga. Integrated high-resolution dataset of high-intensity european and mediterranean flash floods. Earth System Science Data, 10(4):1783-1794, 2018, https://essd.copernicus.org/articles/10/1783/ $2018 /$.

[2] E. Audusse, F. Bouchut, M.-O. Bristeau, R. Klein, and B. Perthame. A fast and stable well-balanced scheme with hydrostatic reconstruction for shallow water flows. SIAM J. Sci. Comput., 25(6):2050-2065, 2004, https://doi.org/10.1137/S1064827503431090.

[3] M. Bermúdez, J. C. Neal, P. D. Bates, G. Coxon, J. E. Freer, L. Cea, and J. Puertas. Quantifying local rainfall dynamics and uncertain boundary conditions into a nested regional-local flood modeling system. Water Resources Research, 53(4):2770-2785, 2017, https://doi.org/10.1002/2016WR019903.

[4] P. Davy, T. Croissant, and D. Lague. A precipiton method to calculate river hydrodynamics, with applications to flood prediction, landscape evolution models, and braiding instabilities. Journal of Geophysical Research: Earth Surface, 122(8):1491-1512, 2017, https://doi.org/10.1002/2016JF004156.

[5] V. Guinot and P. Gourbesville. Calibration of physically based models: back to basics? Journal of Hydroinformatics, 5(4):233-244, 2003, https://doi.org/10.2166/hydro.2003.0020.

[6] A. Kurganov and D. Levy. Central-upwind schemes for the Saint-Venant system. Mathematical Modelling and Numerical Analysis, 36:397-425, 2002, https://doi.org/10.1051/m2an:2002019. 
[7] G. Le Bihan, O. Payrastre, E. Gaume, D. Moncoulon, and F. Pons. The challenge of forecasting impacts of flash floods: test of a simplified hydraulic approach and validation based on insurance claim data. Hydrology and Earth System Sciences, 21(11):5911-5928, 2017, https://doi.org/10.5194/hess-21-5911-2017.

[8] L. Lebouc and O. Payrastre. Reconstitution et analyse des débits de pointe des crues du 3 octobre 2015 dans les Alpes Maritimes. convention dgpr-ifsttar 2016 n 2201030666 du 14 octobre 2016-action 14, https: //hal.archives-ouvertes.fr/hal-01589775. 2017.

[9] P. Nguyen, A. Thorstensen, S. Sorooshian, K. Hsu, A. AghaKouchak, B. Sanders, V. Koren, Z. Cui, and M. Smith. A high resolution coupled hydrologichydraulic model (HiResFlood-UCI) for flash flood modeling. Journal of Hydrology, 541:401-420, 2016. Flash floods, hydro-geomorphic response and risk management, https://doi.org/10.1016/j.jhydrol.2015.10.047.

[10] F. Pons, M. Alquier, and I. Roux. Semi-automatic maps for 2015 french riviera floods. In Philippe Gourbesville, Jean Cunge, and Guy Caignaert, editors, Advances in Hydroinformatics, pages 497-513, Singapore, 2018. Springer Singapore, https ://doi.org/10.1007/978-981-10-7218-5_35.

[11] S. Popinet. Quadtree-adaptative tsunami modelling. Ocean Dynamics, pages 1-25, May 2011, https: //doi.org/10.1007/s10236-011-0438-z.

[12] C. Saint-Martin, P. Javelle, and F. Vinet. Damagis: a multisource geodatabase for collection of floodrelated damage data. Earth System Science Data, 10(2):1019-1029, 2018, https://doi.org/10.5281/ zenodo. 1241089 .

[13] Schapi. Website (www.reperesdecrues.developpement-durable.gouv.fr). edited by le Service central d'hydromét méorologie et d'appui à la prévision des inondations (Schapi), service du Ministère de la transition écologique et solidaire, Réseau VIGICRUES, 2019.

[14] J. Teng, A.J. Jakeman, J. Vaze, B.F.W. Croke, D. Dutta, and S. Kim. Flood inundation modelling: A review of methods, recent advances and uncertainty analysis. Environmental Modelling $\&$ Software, 90:201-216, 2017, https://doi.org/10.1016/j.envsoft.2017.01.006.

[15] Soil Conservation Service USDA. Soil Conservation Service National Engineering Handbook, Supplement A, Section 4, Hydrology: Soil Conservation Service. Soil Conservation Service, USDA Washington, DC, 1956.

[16] W. Zhang and T. W. Cundy. Modeling of two-dimensional overland flow. Water Resources Research, 25(9):2019-2035, September 1989, https://doi.org/10.1029/WR025i009p02019. 